\title{
SENSITIVITY TO SOIL MOISTURE AND OBSERVATION GEOMETRY OF SPACEBORNE GNSS-R DELAY-DOPPLER MAPS
}

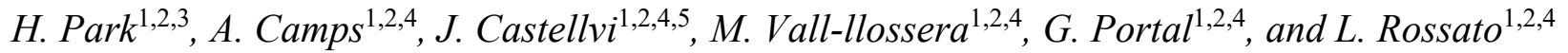 \\ ${ }^{1}$ Unidad de Excelencia María de Maeztu CommSensLab, \\ ${ }^{2}$ Universitat Politècnica de Catalunya and IEEC/UPC, \\ ${ }^{3}$ Dept. Physics, \\ ${ }^{4}$ Dept. Signal Theory and Communications, \\ ${ }^{5}$ Institut Cartogràfic I Geològic de Catalunya \\ Campus Nord, D4, 08034 Barcelona, Spain \\ E-mail: park.hyuk@upc.edu, camps@tsc.upc.edu
}

\begin{abstract}
Thanks to the successful operations of the UK TDS-1 and NASA CYGNSS GNSS-R missions, a wealth of DelayDoppler Maps (DDM) are being measured from the ocean, but also from land reflections. Using the land reflected DDM, several studies are being conducted to retrieve the land geophysical parameters, such as soil moisture, vegetation depth, and biomass. Although they have shown the dependence of the land geophysical parameters on the DDM, it is also shown that many other parameters impact the DDM. This work presents the impacts of some parameters on the DDM. For the systematical and efficient study, an E2E simulator is used. The simulator generates the synthesized DDM reflected over land varying the input parameters, which are the specular point position on the Earth, the elevation angle at the specular points, soil moisture, etc. From the simulation results, the relation between the input parameters and the DDM is individually analyzed, providing the clue to the retrieval algorithm of the geophysical parameters.
\end{abstract}

Index Terms - GNSS reflectometry, DDM, simulator, soil moisture, vegetation

\section{INTRODUCTION}

Recently, many studies are being conducted to expand the GNSS-R technique for the Earth observation using the spaceborne measured data of the UK TDS-1 [1] and NASA CYGNSS [2] missions. For ocean applications, many studies have been reported, e.g., measuring the sea surface roughness, wind speed, and sea surface height [3]-[4]. Land applications are also explored to measure land geophysical parameters. From ground and airborne experiments, it has been reported that the GNSS-R technique is capable of providing the information of soil moisture, vegetation thickness, and biomass [5]-[10]. From spaceborne experiments, several studies have been conducted, and they have shown the feasibility of land geophysical parameter retrievals such as soil moisture from the spaceborne DDM [11]-[15].

Although those studies have demonstrated the feasibility of spaceborne GNSS-R to measure some land geophysical parameters, and in particular soil moisture, the quality of estimated sensitivity is not very good due to several effects linked to the observation geometry and the instrument. For example, the elevation angles, the antenna pattern, the thermal noise level vary the DDM. Topography and surface roughness of the reflected area also affect the GNSS-R measurements. Therefore, further studies of all these effects are needed to demonstrate the feasibility of spaceborne GNSS-R land applications.

This work analyzes the impacts of some parameters to the DDM from spaceborne GNSS-R. Using the developed end-to-end (E2E) simulator, DDMs are generated varying the input parameters, such as elevation angle, soil moisture, and topography of the glistening zone. The variation of the DDM peaks is investigated according to the parameter variation.

\section{METHODOLOGY}

In order to analyze the impact of each parameter efficiently, and independently from other parameters, a GNSS-R E2E simulator for land is needed. In this study, a generic E2E simulator is used for the spaceborne GNSS-R land applications, named "GARCA SIM4Land" [16].

The simulator has been developed and implemented efficiently by using the heritage of spaceborne GNSS-R ocean simulator "GARCA/GEROS-SIM M2" [17] as part of the ESA PARIS-IoD and GEROS-ISS projects. The land simulator uses many parts of the predecessor, e.g., the geometry, the DDM generation, and the instrument modules. 

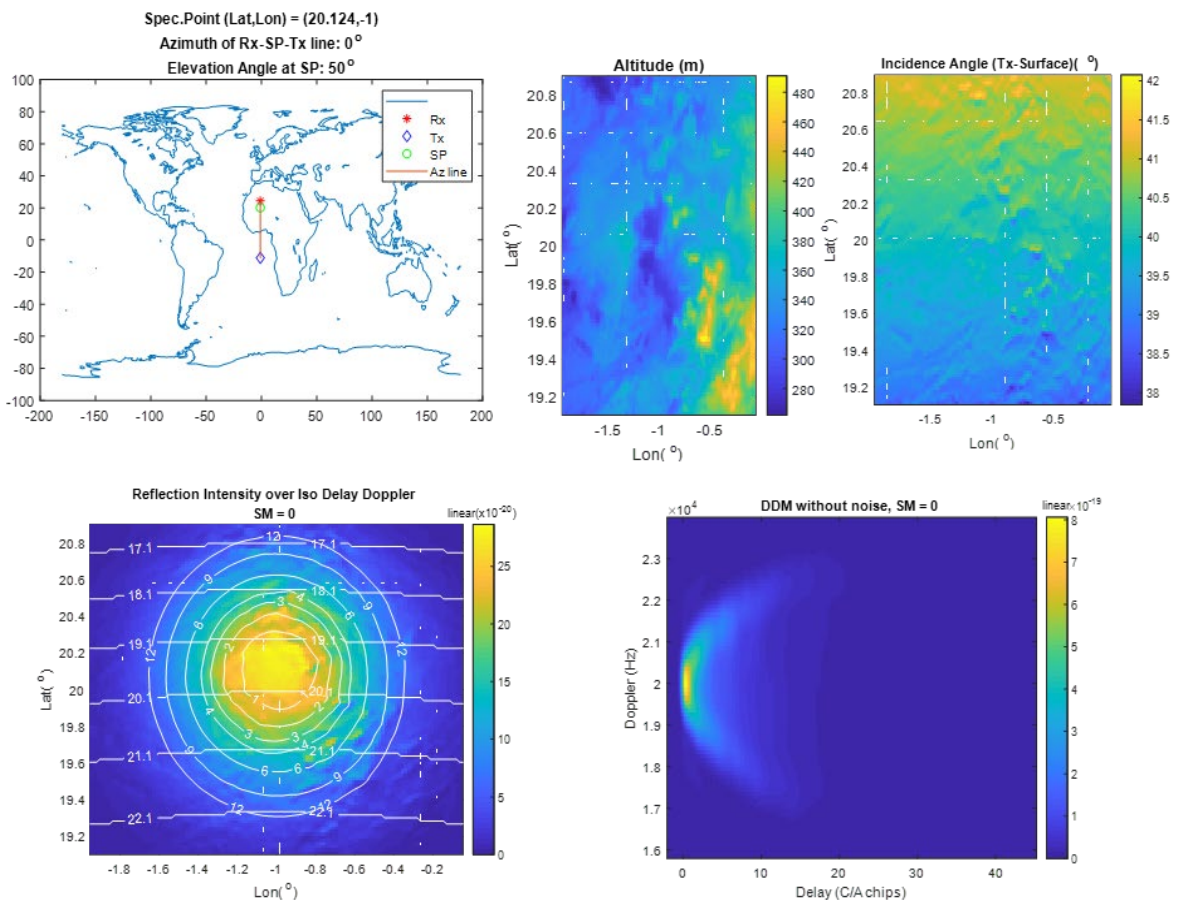

Fig. 1. Example of the simulation results for Sahara: (top-left) observation geometry, (top-middle) altitude, (top-right) local incidence angles, (bottom-left) reflection intensity from the glistening zone, and (bottom-right) resultant DDM

The main module to be replaced is the scene generation module which computes the land reflection coefficients corresponding to the observed scene geophysical parameters. The computed reflection coefficients are further processed to generate the reflection intensities which are observed from the scene by the GNSS-R instrument.

Using the simulator, three input parameters are tested: 1) the topography of the glistening zone, 2) the incidence angle at the specular point, and 3) the soil moisture. All other parameters are set to the ones in TDS-1. Topography is defined by the user by selecting the location of the specular reflection points. Once the location is chosen, i.e. longitude and latitude, the Digital Elevation Model (DEM) of the glistening zone is read from the database (e.g. ETOPO1), and the corresponding geophysical parameters are read from the database constructed in SAIRPS (Synthetic Aperture Interferometric Radiometer Performance Simulator) [18]. For the variable input of the soil moisture, it is set to be homogenous soil moisture around the glistening zone, in this study.

\section{RESULTS}

An example of the simulation results is shown in Fig. 1. The location of the specular point is selected on the Sahara Desert which is relatively flat surface; the maximum altitude variation is around $200 \mathrm{~m}$ (see Fig. 1 top-middle). The reflection intensity in the bottom-left of Fig. 1, means the signal intensity from each ground facet, which is collected by the receiver antenna. It is computed including the reflectivity, path range, and the antenna pattern as well. The received signals are processed producing the DDM in the bottomright of Fig. 1. Here, the thermal noise is not taken into account yet.

The selected DDM observable here is the peak of the DDM, as it is used for soil moisture retrievals. As varying the input parameters, the DDM peak values are recorded in each simulation.

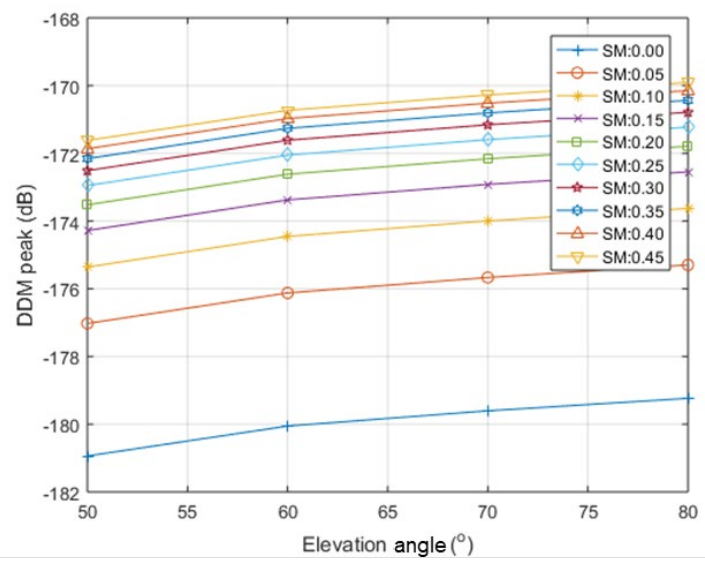

Fig. 2. DDM peak values according to the elevation angle and the soil moisture for the simulation of Sahara. 
The results of Sahara simulation are summarized in Fig. 2. The elevation angles at the specular points are varying from $50^{\circ}$ to $80^{\circ}$, and correspondingly the DDM peak values increase by around $2 \mathrm{~dB}$. The colored markers of the lines stand for the results according to the soil moisture ranging from 0 to $0.45 \mathrm{~m}^{3} / \mathrm{m}^{3}$ in steps of $0.05 \mathrm{~m}^{3} / \mathrm{m}^{3}$. The DDM peaks increase with the soil moisture, and in Fig. 2 it is larger by $9.5 \mathrm{~dB}$ in the case of SM of 0.45 as compared to the SM of 0 . The trends of the DDM peak increasing with the elevation angle are quite similar regardless of the soil moisture value.

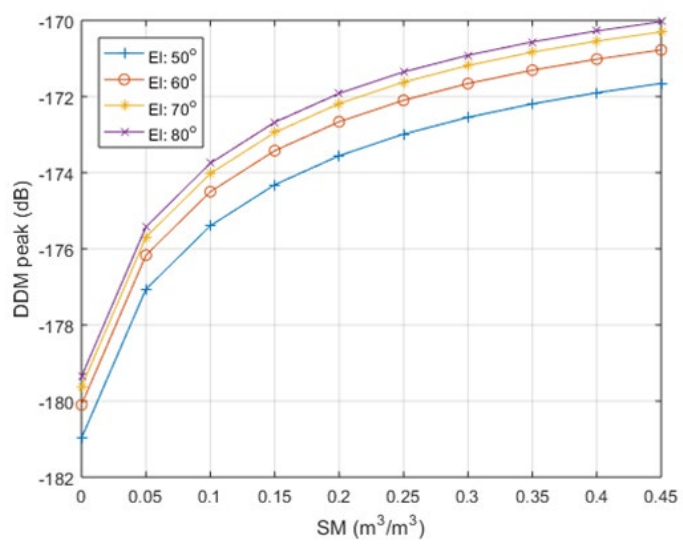

Fig. 3. DDM peak values with respect to the soil moisture for the simulation of Sahara

The results are presented in Fig. 3 for display of the soil moisture trend. For all the cases of the elevation angles, the trends of the DDM peak are similar; increasing with the soil moisture. From the soil moisture of 0 to $0.45 \mathrm{~m}^{3} / \mathrm{m}^{3}$, the DDM peak increase by $9.5 \mathrm{~dB}$. The relation between the soil moisture and the DDM peak (in $\mathrm{dB}$ ) is not linear. In dry soils $(0-0.1)$, the DDM peaks increase with the soil moisture value quite rapidly, but as the soil gets wet, the slope decreases.

In Fig. 4, simulation results in the Pyrenees is presented. It exhibits a high altitude deviation (from 350 to $1900 \mathrm{~m}$ ). Corresponding to the large changes in the elevation, the isodelay line is very irregular (Fig. 4, top-right panel). The reflection intensity is also very irregular shape, as compared to the flat region in Fig. 1, as each individual "facet" of the surface has its own orientation. Consequently, the DDM shape is not a regular horseshoe, and it shows some anomalies, e.g., the peak is not exactly the specular reflection position etc.

The simulation of the DDM peak is shown in Fig. 5 with respect to the soil moisture value, and the elevation angle. The DDM peaks increase with increasing soil moisture and elevation angle, as for the Sahara region in Fig. 3. The trend is also similar: larger slope (sensitivity) for dry soils, as compared to wet soils. However, the actual increase is different from the low altitude deviation case (flat surface). The deviation of the DDM peak between the elevation angles of $50^{\circ}$ to $80^{\circ}$ is $1 \mathrm{~dB}$ in Fig. 5, which is smaller than in Fig. 3. The deviation about the soil moisture is also smaller $(\sim 9$ $\mathrm{dB}$ from 0 to $\left.0.45 \mathrm{~m}^{3} / \mathrm{m}^{3}\right)$ in Fig. 5 than in Fig $6(\sim 9.5 \mathrm{~dB})$. It means that the impacts of the elevation angle and the soil moisture are smaller in the large altitude varying region compared to the low case, as topography is hiding these effects.

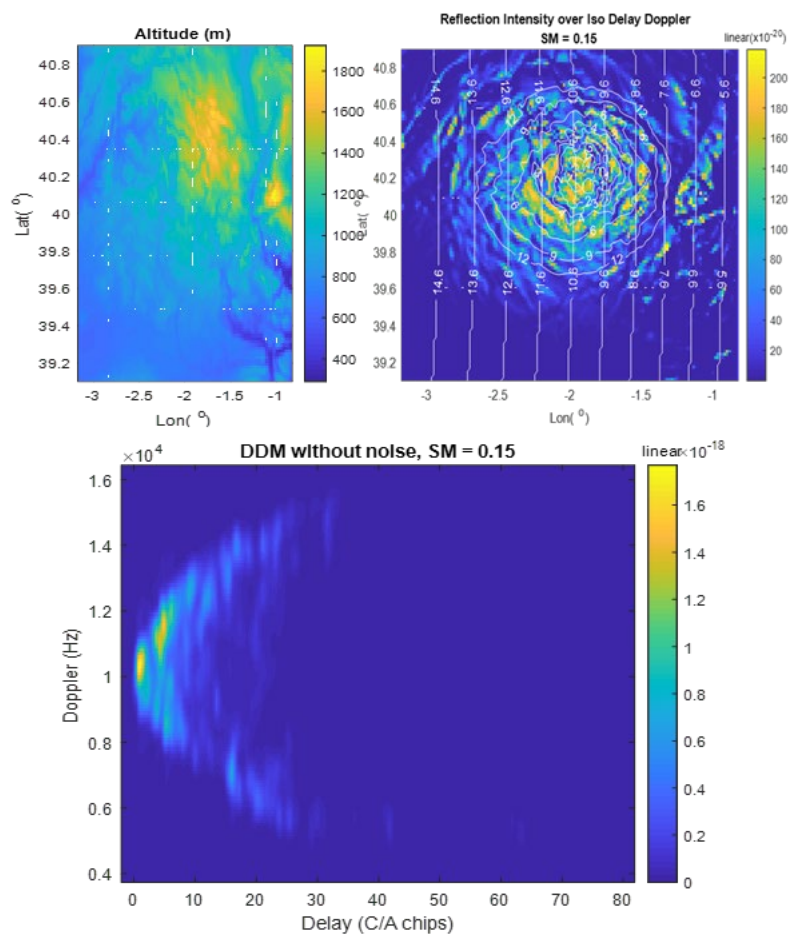

Fig. 4. Example of the simulation results for the Pyrenees: (top-middle) altitude, (top-right) reflection intensity from the glistening zone, and (bottom) resultant DDM.

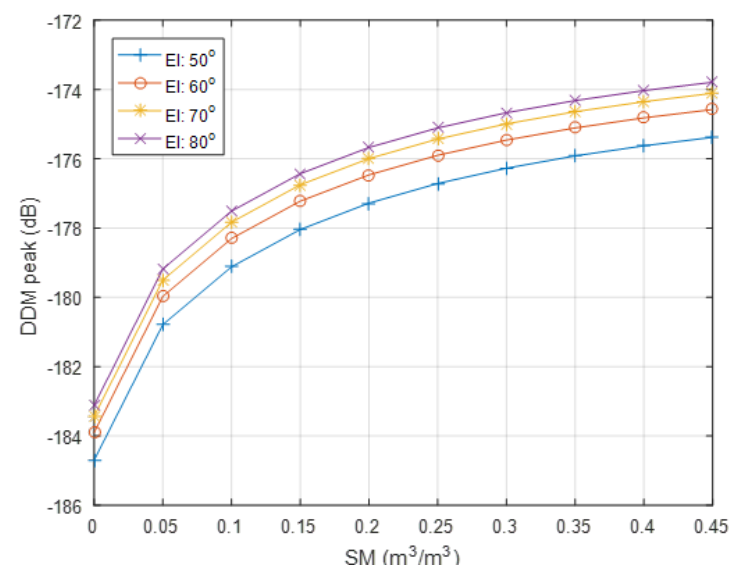

Fig. 5. DDM peak values with respect to the soil the soil moisture for the simulation of the Pyrenees 


\section{CONCLUSIONS}

Several GNSS-R missions are planned to exploit this new opportunity for the Earth observation. The feasibility for land geophysical parameters is being investigated by several studies. These studies have shown that the measured DDM is affected by many parameters in a way that is difficult to understand. These effects degrade the performance of the parameter retrieval, as it is difficult to correct them. This work has presented the impact of the soil moisture and the elevation angle on the GNSS-R DDM peak observable using the E2E simulator.

The developed simulator allows to study the dependency of the DDMs with respect to the individual parameters such as the soil moisture. Many other influential parameters can also efficiently analyzed for their impacts on the DDM, e.g., the elevation angles, land cover, topography. In this study, the variation of DDM peak has been tested with respect to the elevation angle, topography, and the soil moisture.

The study of these impacts can be used to devise the tailored retrieval algorithm with error budget.

\section{ACKNOWLEDGEMENTS}

The simulator development has been supported by the Agencia Estatal de Investigacion, Spain, and Unidad de Excelencia Maria de Maeztu MDM-2016-0600. This simulator will be supporting ESA study ESA/ESTEC CONTRACT no. 4000120299/17/NL/AF/hh "Potential of spaceborne GNSS-R for land applications".

\section{REFERENCES}

[1] M. Unwin, P. Jales, J. Tye, C. Gommenginger, G. Foti, and J. Rosello, "Spaceborne GNSS-Reflectometry on TechDemoSat-1: Early Mission Operations and Exploitation," IEEE J. Sel. Top. Appl. Earth Obs. Remote Sens., vol. 9, no. 10, pp. 4525-4539, Oct. 2016.

[2] C. S. Ruf, et al., "New Ocean Winds Satellite Mission to Probe Hurricanes and Tropical Convection," Bull. Am. Meteorol. Soc., vol. 97, no. 3, pp. 385-395, Mar. 2016.

[3] G. Foti, C. Gommenginger, M. Unwin, P. Jales, J. Tye, and J. Rosello, "An Assessment of Non-geophysical Effects in Spaceborne GNSS Reflectometry Data From the UK TechDemoSat-1 Mission," IEEE J. Sel. Top. Appl. Earth Obs. Remote Sens., vol. 10, no. 7, pp. 3418-3429, Jul. 2017.

[4] R. Balasubramaniam, C. S. Ruf, D. McKague, M. P. Clarizia, and S. Gleason, "Calibration and validation processing for the CYGNSS wind speed retrieval algorithm," in IEEE IGARSS, 2017, pp. 4117-4120.

[5] S. V. Nghiem, C. Zuffada, R. Shah, C. Chew, S. T. Lowe, A. J. Mannucci, E. Caet al., "Wetland monitoring with Global Navigation Satellite System reflectometry," Earth Sp. Sci., vol. 4, no. 1, pp. 1639, 2017.
[6] E. Motte, M. Zribi, P. Fanise, A. Egido, J. Darrozes, A. AlYaari, N. Baghdadi, F. Baup, S. Dayau, R. Fieuzal, P. L. Frison, D. Guyon, and J. P. Wigneron, "GLORI: A GNSS-R dual polarization airborne instrument for land surface monitoring," Sensors (Switzerland), vol. 16, no. 5, 2016.

[7] A. Egido, S. Paloscia, E. Motte, L. Guerriero, N. Pierdicca, M. Caparrini, E. Santi, G. Fontanelli, and N. Floury, "Airborne GNSS$\mathrm{R}$ polarimetric measurements for soil moisture and above-ground biomass estimation," IEEE J. Sel. Top. Appl. Earth Obs. Remote Sens., vol. 7, no. 5, 2014.

[8] A. Alonso-Arroyo, A. Camps, A. Monerris, C. Rudiger, J. P. Walker, G. Forte, D. Pascual, H. Park, and R. Onrubia, "The light airborne reflectometer for GNSS-R observations (LARGO) instrument: Initial results from airborne and Rover field campaigns," in IEEE IGARSS 2014, 2014.

[9] A. Alonso-Arroyo, A. Camps, A. Monerris, C. Rudiger, J. P. Walker, R. Onrubia, J. Querol, H. Park, and D. Pascual, "On the Correlation Between GNSS-R Reflectivity and L-Band Microwave Radiometry,” IEEE J. Sel. Top. Appl. Earth Obs. Remote Sens., vol. 9, no. 12, pp. 5862-5879, Dec. 2016.

[10] Y. Jia and P. Savi, "Sensing soil moisture and vegetation using GNSS-R polarimetric measurement," Adv. Sp. Res., vol. 59, no. 3, pp. 858-869, Feb. 2017.

[11] A. Camps, H. Park, M. Pablos, G. Foti, C. P. Gommenginger, P.-W. Liu, and J. Judge, "Sensitivity of GNSS-R Spaceborne Observations to Soil Moisture and Vegetation," IEEE J. Sel. Top. Appl. Earth Obs. Remote Sens., vol. 9, no. 10, pp. 4730-4742, Oct. 2016.

[12] C. Chew, R. Shah, C. Zuffada, G. Hajj, D. Masters, and A. J. Mannucci, "Demonstrating soil moisture remote sensing with observations from the UK TechDemoSat-1 satellite mission," Geophys. Res. Lett., vol. 43, no. 7, pp. 3317-3324, Apr. 2016.

[13] A. Camps, M. Vall·llossera, H. Park, G. Portal, L. Rossato, A. Camps, M. Vall-llossera, H. Park, G. Portal, and L. Rossato, "Sensitivity of TDS-1 GNSS-R Reflectivity to Soil Moisture: Global and Regional Differences and Impact of Different Spatial Scales," Remote Sens., vol. 10, no. 11, p. 1856, Nov. 2018.

[14] H. Carreno-Luengo, G. Luzi, M. Crosetto, "Impact of the Elevation Angle on CYGNSS GNSS-R Bistatic Reflectivity as a Function of Effective Surface Roughness over Land Surfaces," Remote Sens., vol. 10, no. 11, p. 1749, Nov. 2018

[15] C. C. Chew and E. E. Small, "Soil Moisture Sensing Using Spaceborne GNSS Reflections: Comparison of CYGNSS Reflectivity to SMAP Soil Moisture," Geophys. Res. Lett., vol. 45, no. 9, pp. 4049-4057, May 2018.

[16] H. Park, A. Camps, D. Pascual, A. Alonso-Arroyo, J. Querol, and R. Onrubia, "Improvement of PAU/PARIS end-to-end performance simulator (P2EPS): Land scattering including topography," in IEEE IGARSS 2019, 2016, pp. 5607-5610.

[17] H. Park, A. Camps, D. Pascual, Y. Kang, R. Onrubia, J. Querol, and A. Alonso-Arroyo, "A Generic Level 1 Simulator for Spaceborne GNSS-R Missions and Application to GEROS-ISS Ocean Reflectometry," IEEE J. Sel. Top. Appl. Earth Obs. Remote Sens., vol. 10, no. 10, pp. 4645-4659, Oct. 2017.

[18] A. Camps, H. Park, Y. Kang, J. Bandeiras, J. Barbosa, P. Vieira, A. Friaças, and S. d'Addio, "Microwave Imaging Radiometers by Aperture Synthesis Performance Simulator (Part 2): Instrument Modeling, Calibration, and Image Reconstruction Algorithms,” J. Imaging, vol. 2, no. 2, p. 18, May 2016. 